UCRL-JC-130514

PREPRINT

\title{
Fatigue of LX-14 and LX-19 Plastic Bonded Explosives
}

\author{
D. Mark Hoffman
}

This paper was prepared for submittal to the

JOWOG 9, Aldermaston, England

June 22-26, 1998

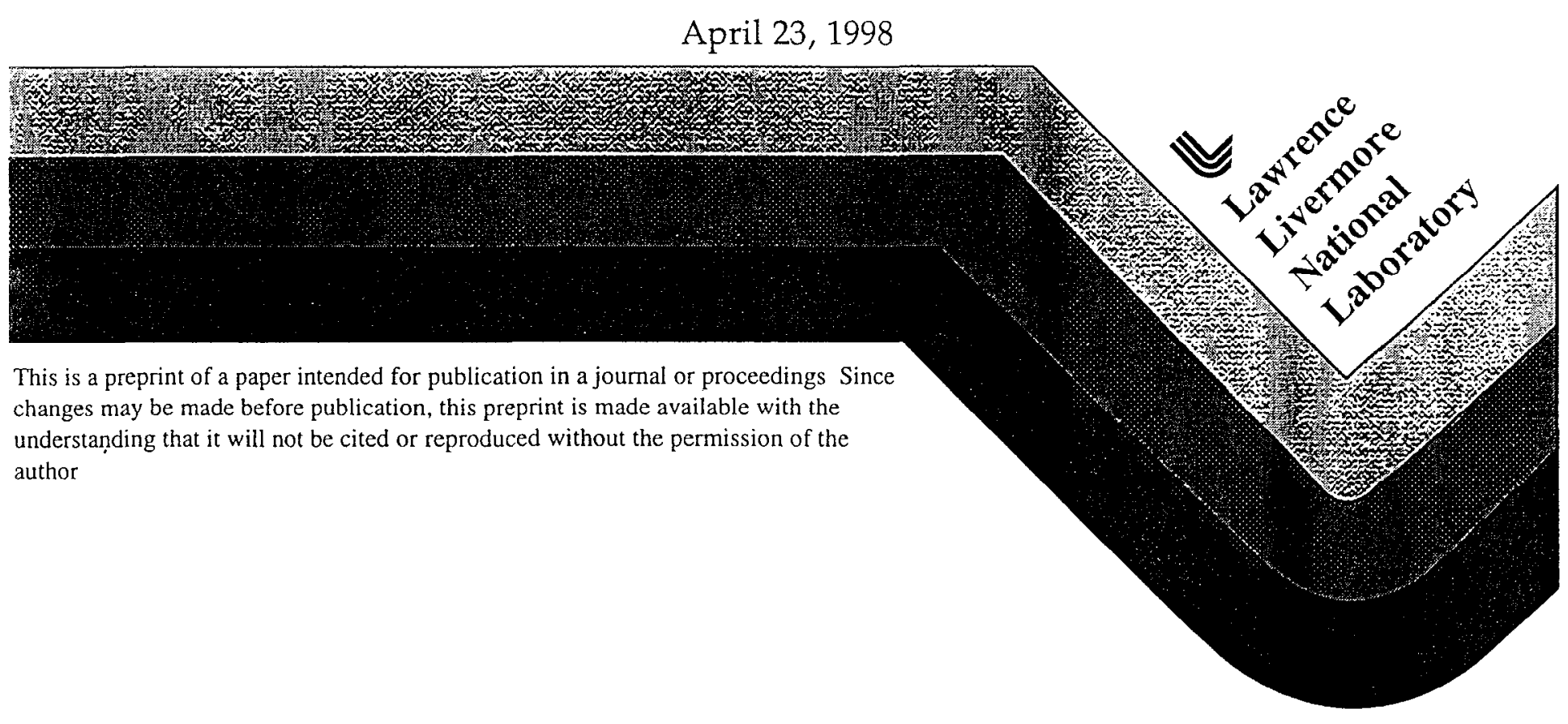




\section{DISCLAIMER}

This document was prepared as an account of work sponsored by an agency of the United States Government. Neither the United States Government nor the University of California nor any of their employees, makes any warranty, express or implied, or assumes any legal liability or responsibility for the accuracy, completeness, or usefulness of any information, apparatus, product, or process

disclosed, or represents that its use would not infringe privately owned rights. Reference herein to any specific commercial product, process, or service by trade name, trademark, manufacturer, or otherwise, does not necessarily constitute or imply its endorsement, recommendation, or favoring by the United States Government or the University of California. The views and opinions of authors expressed herein do not necessarily state or reflect those of the United States Government or the University of California, and shall not be used for advertising or product endorsement purposes. 
Fatigue of LX-14 and LX-19 Plastic Bonded Explosives

\author{
D. Mark Hoffman \\ Lawrence Livermore National Laboratory \\ (510) $422-7759$ \\ hoffman2@1lnl.gov
}

\begin{abstract}
The DOD uses the plastic bonded explosive (PBX) LX-14 in a wide variety of applications including shaped charges and explosively forged projectiles. ${ }^{1}$ LX19 is a higher energy explosive, which could be easily substituted for LX-14 because it contains the identical Estane 5703p binder and more energetic CL-20 explosive. Delivery systems for large shaped charges, such as TOW-2, include the Apache helicopter. Loads associated with vibrations and expansion from thermal excursions in field operations may, even at low levels over long time periods, cause flaws, already present in the PBX to grow. Flaws near the explosive/liner interface of a shaped charge can reduce performance. Small flaws in explosives are one mechanism (the hot spot mechanism) proposed for initiation and growth to detonation of PBXs like LX-14, PBXN 5, LX-04 and LX-17 among others. Unlike cast-cured explosives and propellants, PBXs cannot usually be compression molded to full density. Generally, the amount of explosive ignited by a shock wave is approximately. equal to the original void volume. ${ }^{2}$ Whether or not these flaws or cracks grow during field operations to an extent sufficient to adversely affect the shaped charge performance or increase the vulnerability of the PBX is the ultimate question this effort could address. Currently the fatigue life of LX-14 under controlled conditions is being studied in order to generate its failure stress as a function of the number of fatigue cycles (S$\mathrm{N}$ curve). Proposed future work will address flaw and crack growth and their relationship to hot-spot concentration and explosive vulnerability to shock and/or fragment initiation.
\end{abstract}

\title{
Experimental
}

\section{Explosive Preparation}

LX-14 and LX-19, whose compositions are listed in Table 1, were compression molded into right circular cylinders approximately $50.8 \mathrm{~mm}(2$ inches) in diameter by $25.4 \mathrm{~mm}$ ( 1 inch) high (approximately $100 \mathrm{~g}$ of explosive). Two lots (C-211 and C-181) of LX-14 explosive made in 1996 and 1988, respectively, were evaluated. RM-03-AC mock was used extensively in the preliminary setup and proof-out of the system and testing procedures. Theoretical and average nominal densities of the pressings are also given in the 
die temperature of $98^{\circ} \mathrm{C}$ and $200 \mathrm{MPa}(30,000 \mathrm{psi})$ were used with 3 minute dwells at no pressure between each pressure cycle. All parts were molded under approximately 40 -micron vacuum..$^{3}$

Table 1. Compositions and densities of plastic bonded explosives.

\begin{tabular}{ccccccc}
\hline PBX & lot no. & Binder & Explosive & wt ratio & $\rho(\mathrm{TMD})$ & $\rho($ nom $)$ \\
\hline LX-14 & C-181 & Estane 5703p & HMX & $4.5 / 95.5$ & 1.8538 & 1.829 \\
LX-14 & C-211 & Estane 5703p & HMX & $4.5 / 95.5$ & 1.8538 & 1.823 \\
LX-19 & C-205 & Estane 5703p & CL-20 & $4.2 / 95.8$ & 1.983 & 1.927 \\
RM-03-AC & & KF-800 & none & $15 / 85$ & $1.89^{*}$ & $1.82^{\star *}$ \\
\hline * Estimated from average literature data. ${ }^{* *}$ Larger variation in density $( \pm 0.03)$
\end{tabular}

Fatigue testing

A $380 \mathrm{MPa}$ (55 Kip) MTS hydraulic test machine model 880 with computer control Teststar II data acquisition and Testware SX test generation software was used for all experiments. ${ }^{4}$ After several unsuccessful attempts to make strain-controlled fatigue measurements ${ }^{5}$ with this software, load control was used. A special fixture shown in Figure 1 was designed to hold a

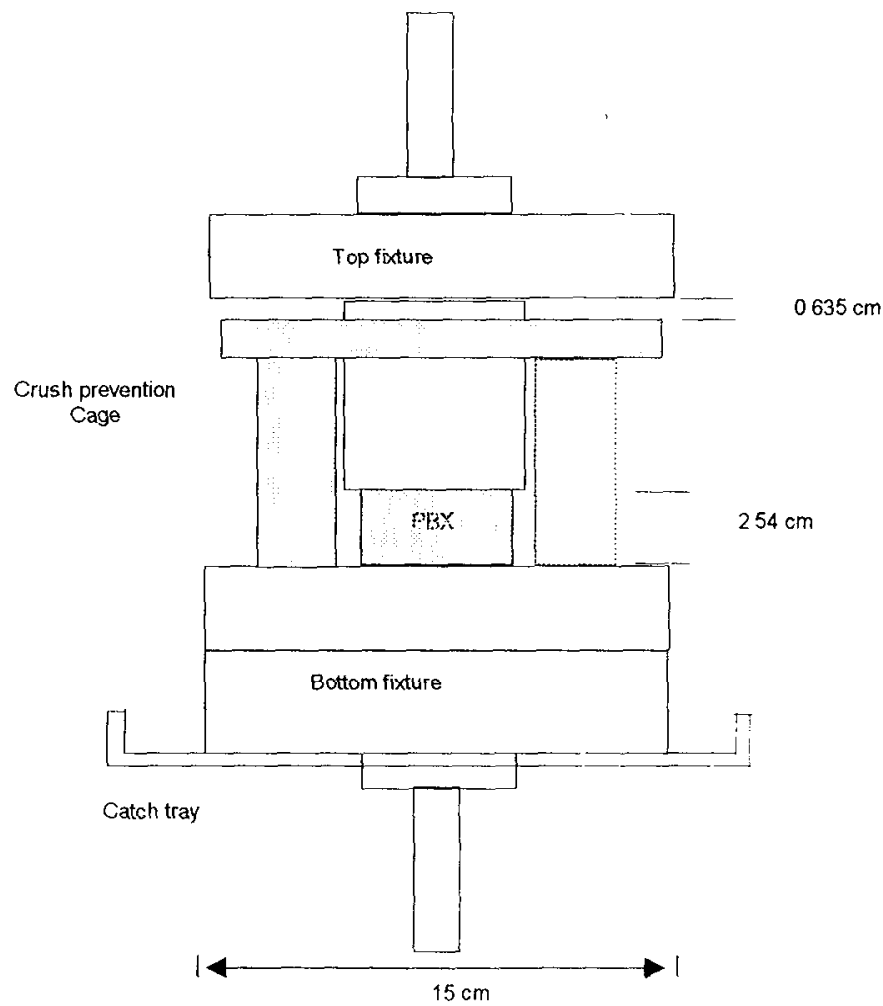

Figure 1. Fixture and setup for PBX fatigue testing prevents metal to metal contact by a crush prevention cage and collects any explosive debris generated in the fracture process in a catch tray. 
cylindrical explosive specimen but prevent excessive stress on the explosive in the event of hydraulic failure or explosive fracture. The fixture is mounted in 22 Kip hydraulic grips. The compression plate on the actuator is lowered to allow about a $0.5-\mathrm{mm}$ gap between explosive and fixturing. Load, stroke and strain minimum/maximum interlocks are set to $\pm 6.9 \mathrm{MPa}(10 \mathrm{Ksi}), \pm 1.27 \mathrm{~cm}(0.5 \mathrm{in})$, and $\pm 6.35 \mathrm{~cm}(0.25 \mathrm{in})$, respectively. $\Lambda$ sample is compressed to failure and the engineering stress and strain are recorded digitally on a computer. Subsequently, samples are fatigued under sinusoidal stress up to $-13.2 \mathrm{MPa}$ (1900 psi) or about $20 \%$ of the ultimate strength. Under stress control, test variables are described in accordance with Figure 2. Definitions are given below $^{6-7}$ :

$$
\begin{aligned}
& \Delta \sigma=\text { stress range }=\sigma(\max )-\sigma(\min ) \\
& \sigma_{\mathrm{a}}=\text { stress amplitude }=[\sigma(\max )-\sigma(\min )] / 2=\Delta \sigma / 2 \\
& \sigma_{\mathrm{m}}=\text { mean stress }==[\sigma(\max )+\sigma(\min )] / 2 \\
& \mathrm{R}=\text { stress ratio }=\sigma(\min ) / \sigma(\max )
\end{aligned}
$$

Using these definitions and a negative sign to imply compression, the fatigue measurements were made over a stress range up to $12.9 \mathrm{MPa}$ (1878 psi) for up to $10^{6}$ cycles at $1 \mathrm{~Hz}$ or until failure. The maximum stress amplitude was 6.44 $\mathrm{MPa}(939 \mathrm{psi})$ with a mean stress of $-6.69 \mathrm{MPa}(-970 \mathrm{psi})$ and stress ratio of 60. An MTS 630-20 compression-tension extensometer was modified to allow attachment to the explosive by insertion into the fixture with a gauge length of $1.7 \mathrm{~cm}$. The extensometer was recalibrated and readout corrected for the new

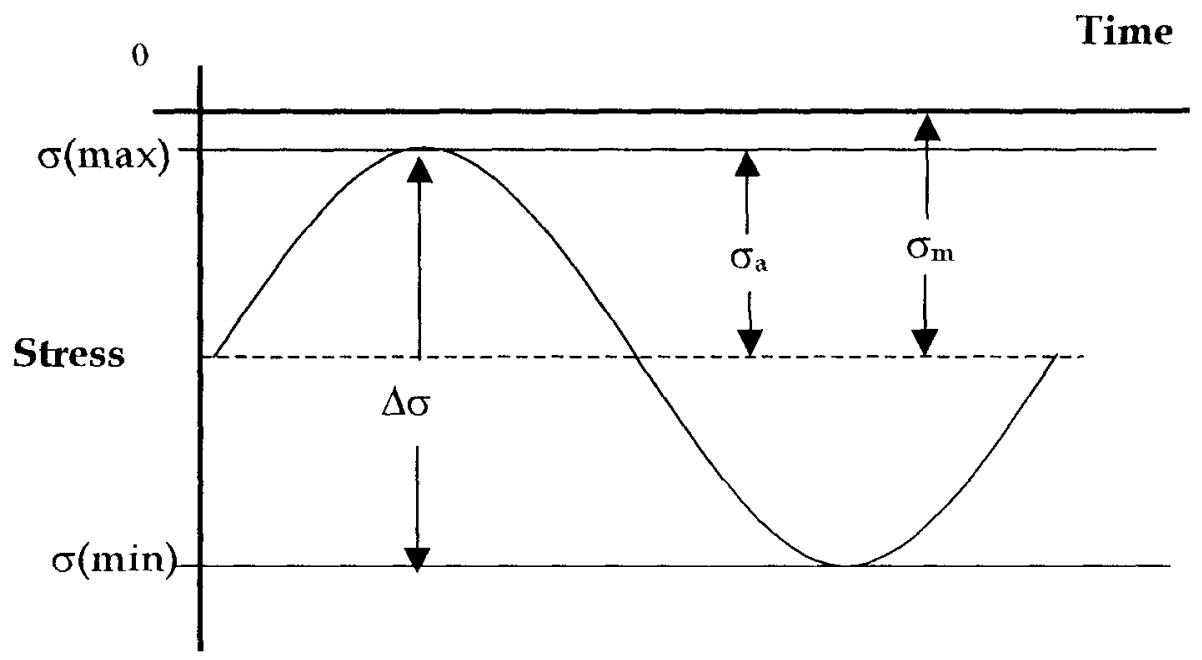

Figure 2. Definitions of variables associated with compressive cyclic loading. 
gauge length. Fatigue testing of all explosives was done remotely in a cell in the High Explosives Application Facility (HEAF) at Lawrence Livermore National Laboratory.

\section{Optical Microscopy}

A Zeiss polarizing microscope with epi illumination was used to obtain optical micrographs of the surface cracks of fatigued and statically fractured samples. Dimensions were calibrated against a stage micrometer. Marker bars in the photomicrographs are $1 \mathrm{~mm}\left(10^{3}\right.$ micrometers $)$.

\section{Results and Discussion}

Preliminary setup and procedures were developed from RM-03-AC mock explosive formulated under different conditions but compression molded

according to the LX-17 procedure ${ }^{8}$. This mock explosive showed widely varying mechanical properties. Fatigue testing of the mock showed crack development and reduced mechanical properties well before static failure stresses. The flaws and cracks which developed were sufficiently small that they could easily be overlooked by visual inspection, but optical micrographs reveal long (almost 1 $\mathrm{mm}$ ), thin cracks at approximately 35-45 degrees from the loading direction. To minimize variability associated with formulation, single lots were used in each PBX test series as indicated in Table 1.

\section{LX-14 and LX-19 plastic bonded explosize compressive strength.}

Data for LX-14 and LX-19 were generated in the same manor as the mock explosive. Stress-strain curves were generated in compression on cylindrical specimens identical to those tested in fatigue at an actuator speed of 0.127 $\mathrm{mm} / \mathrm{min}(0.05 \mathrm{in} / \mathrm{min})$. Because surface flaws tend not to propagate in compression, yield and ultimate strengths are easier to measure. Figure 3 shows the static stress-strain curves for LX-14 and LX-19 generated from the fatigue cylinders. More extensive static test results for LX-14 are given elsewhere9. The static mechanical propertics obtained from the figure are given in Table 2. Occasionally the modified extensometer would slip during testing, as shown in Figure 3, when the specimens barreled and failed. When this happened erroneous results were obtained and calculations could only be made directly from the load versus stroke data. In this case, higher values of strain were obtained, resulting in lower modulus values as indicated in the table by an asterisk. The Young's moduli measured using the total travel/initial height 
differed from strain measurements using the extensometer according to the relationship: $\mathrm{E}_{\mathrm{y}}$ (stroke) $\approx 0.42 \bullet \mathrm{E}_{\mathrm{y}}($ strain $)$.

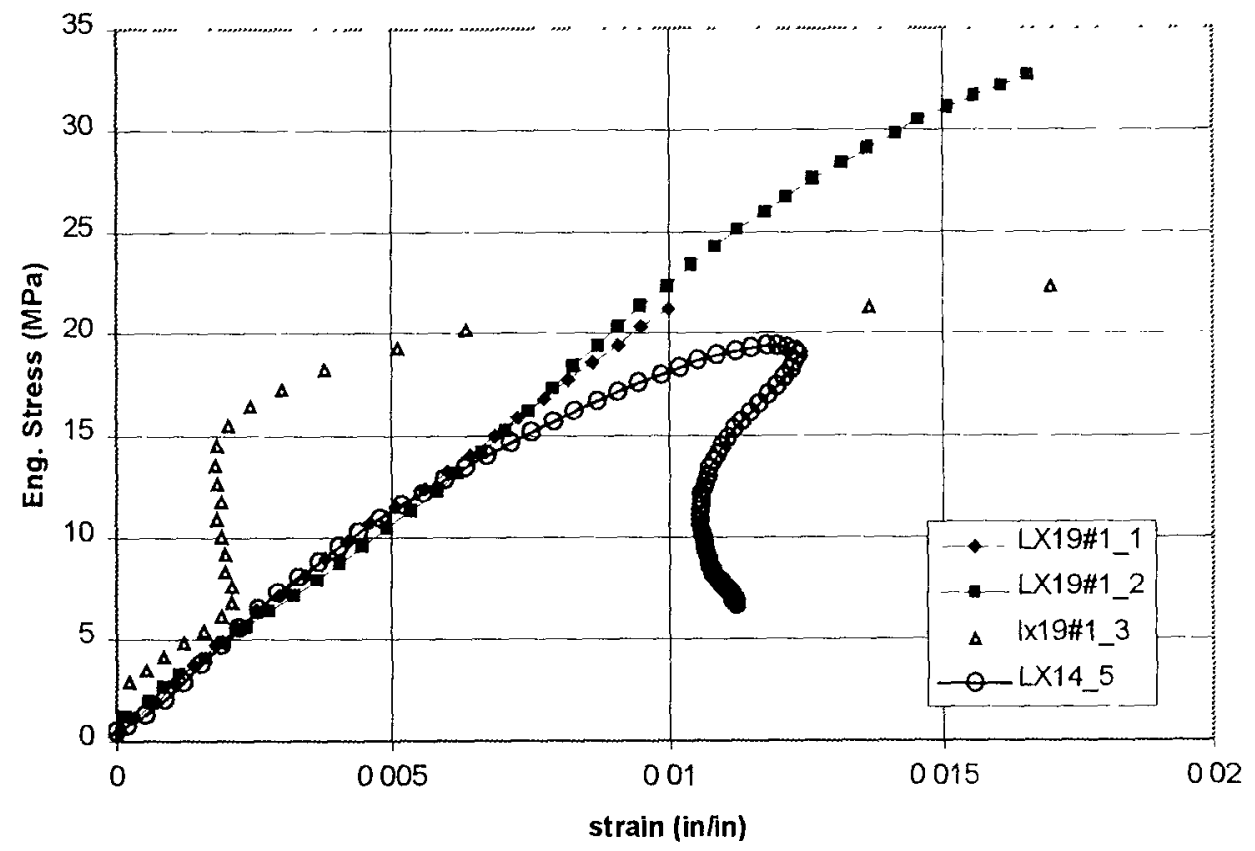

Figure 3. Static stress-strain measurements for LX-19 and LX-14 show similar moduli but different strengths. The same LX-19 sample was tested 3 times in succession at increasing loads as indicated by _1, 2, and _ 3 . The extensometer slipped during the final test (triangles).

Table 2. Static compressive properties of Mock and Estane 5703p explosives.

\begin{tabular}{llllll} 
Sample & $\mathrm{E}_{\mathrm{y}}(\mathrm{GPa})$ & $\sigma(\mathrm{y})(\mathrm{MPa})$ & $\varepsilon(\mathrm{y})(\%)$ & $\mathrm{E}_{\mathrm{y}}(\mathrm{GPa})^{*}$ & $\varepsilon(\mathrm{y})(\%)$ \\
\hline RM-03-AC & 2.27 & 30.3 & & & \\
LX-14 (C-181) & 2.24 & 19.4 & 0.82 & 0.94 & 2.80 \\
LX-14 (C-211) & $1.16^{*}$ & & & & \\
LX-19 (C-205) & 2.05 & 34.0 & $<1.65^{*}$ & 0.90 & 4.03 \\
\hline
\end{tabular}

where Ey is Young's modulus, $\sigma(y)$ is the yield strength, $\varepsilon(y)$ is the strain at yield and * indicates properties measured using $\varepsilon=$ Stroke $/ L_{o}$ rather than strain gauge measurement. -Fstimated from first cycle fatigue data.

As Figure 3 shows, LX-14 from lot C-181 and LX-19 from lot C-205 had nearly identical moduli at ambient, but LX-14 failed at nearly $40 \%$ lower strain to failure and stress at break. Since LX-14 and LX-19 were formulated to constant volume of binder, this is consistent with aging of the LX-14 prior to pressing. Binder aging due to chain scission or slight crosslinking should not dramatically affect the modulus of a PBX. As is well known, the mechanical properties of Estane 5703 $\mathrm{p}^{9-13}$ and its PBX formulations like LX-14 and LX-19 
deteriorate with time. ${ }^{14-18}$ The effects of aging vary, but tests by Scribner ${ }^{16}$ indicate similar reductions in strength associated with thermally accelerated aging. To verify this assertion, specimens were prepared from a new lot (C-211) made at Holston in 1996. Unfortunately, this formulation was softer (lower modulus) than the LX-14 stored for 8 years. This result left us in a quandary. Differences in interfacial bonding between Estane 5703p and HMX in LX-14 as opposed to and CL-20 in LX-19 could also improved yield and elongation behavior. Explosive/binder interfacial interactions can affect the processability and mechanical strength of the PBX.19-21 Definitive information on the interfacial interactions between Estane 5703p and CL-20 versus HMX is unavailable at present, so this effect cannot be confirmed. The reduction in the modulus of new versus old LX-14 may be due to changes in the preparation technique used at Holston today and 8 years ago. The processing solvent for a microphase separated polyester urethane binder, such as Estane 5703p, will influence the properties of the resulting cast film. ${ }^{22,23}$ Formulation in a Holston Reactor involves dissolving Estane 5703p in a solvent. Several solvents have been used in the past. Initially, LX-14 was prepared using ethylene dichloride, which has a solubility parameter ${ }^{24,25}$ of $17.5(\mathrm{j} / \mathrm{cc})^{1 / 2}$. Because of environmental concerns associated with chlorinated hydrocarbons, ethyl acetate, $18.6(\mathrm{j} / \mathrm{cc})^{1 / 2}$, was used to formulate LX-19, and Holston currently uses methyl ethyl ketone, 19.0 $(\mathrm{j} / \mathrm{cc})^{1 / 2}$, in the formulation of LX-14. The higher solubility parameters of methyl ethyl ketone could solubilize the hard segment while the lower solubility parameter would tend to solubilize the soft segment portion of the polyesterurethane. Poor hard segment phase separation would reduce the modulus of the binder, consistent with observations for LX-14. The reason for the reduced modulus in lot C-211 remains speculation at best. The arguments associated with changes in processing solvent are consistent with the modulus changes in LX-14. The reduced strength of both lots of LX-14 makes the suggestion that aging is responsible for reduced strength of old LX-14 compared to new LX-19 tenuous at best. However, the abundance of literature data showing reduced strength at constant modulus for LX-14 are consistent with that explanation. It also suggests that LX-14 or LX-19 should be stored in humidity controlled magazines.

Some concern regarding the applicability of linear viscoelasticity, elasticplastic and thermorheologically simple models to plastic bonded explosives revolves around the results found in cast-cured explosives and propellants. ${ }^{26-28}$ These explosives and propellants are damaged at very low strains and do not recover their initial stress-strain characteristics until the original strain has been exceeded. As shown in Figure 3 for the same LX-19 specimen stressed three times to 20.7, 32.9 and $34 \mathrm{MPa}$ (failure), respectively, the stress strain curves fall on nearly the same trace indicating that in compression these materials are reasonably well behaved and that these types of models might be appropriate. 


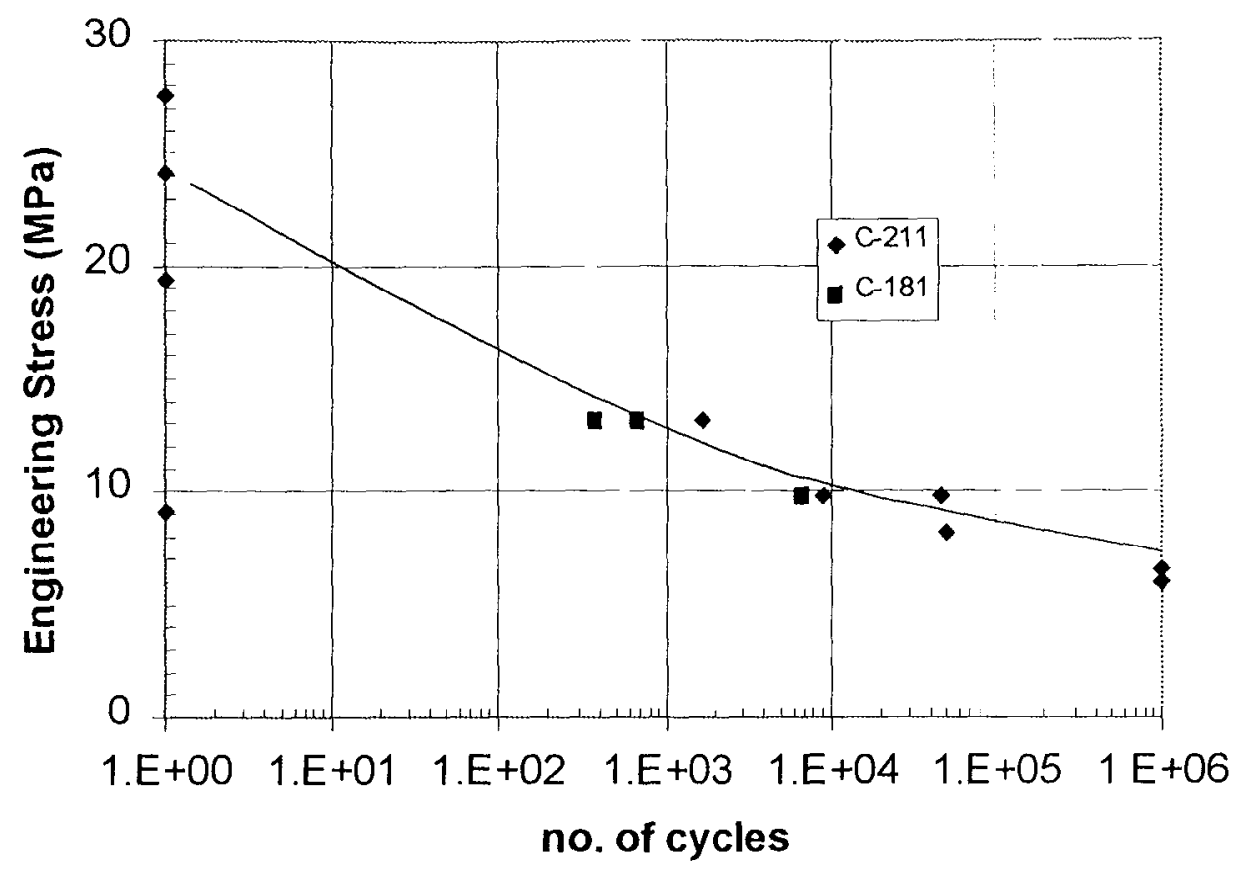

Figure 4. One S-N curve for LX-14 in compression was drawn through C-181 (diamond) and C-211 (square) data at ambient at $1 \mathrm{~Hz}$. Older LX-14 data is almost always to the right of the curve and newer LX-14 data to the left.

Fatigue characteristics of LX-14 from 1 and 8 year old molding powder.

$\dot{\mathrm{S}}-\mathrm{N}$ curves for LX-14 from lot C-181 and C-211 are shown in Figure 4. The LX-14 S-N curve is similar in shape to that of the LX-19 but shifted to lower failure stress values by about $20 \%$. The LX-14 samples tested at stresses below 6.6 $\mathrm{MPa}$ (1000 psi) survived $10^{6}$ cycles without failing, so the curve passed slightly above these points. Since pressed parts have some variability in density (implying some distribution in flaws ${ }^{6}$ ), there is some scatter in the data. These points were evaluated based on the number of cycles to complete failure, i.e., the explosive specimen was fractured radially as shown in Figure 5. As will be discussed below, significant changes in the modulus, hysteresis loop, and irreversible deformation occurred throughout these experiments. Only in the last few dozen cycles was the servohydraulic feedback control unable to maintain a nearly sinusoidal load. This seems to imply that there is minimal contribution from thermal fatigue, found in low cycle fatigue measurements.? 

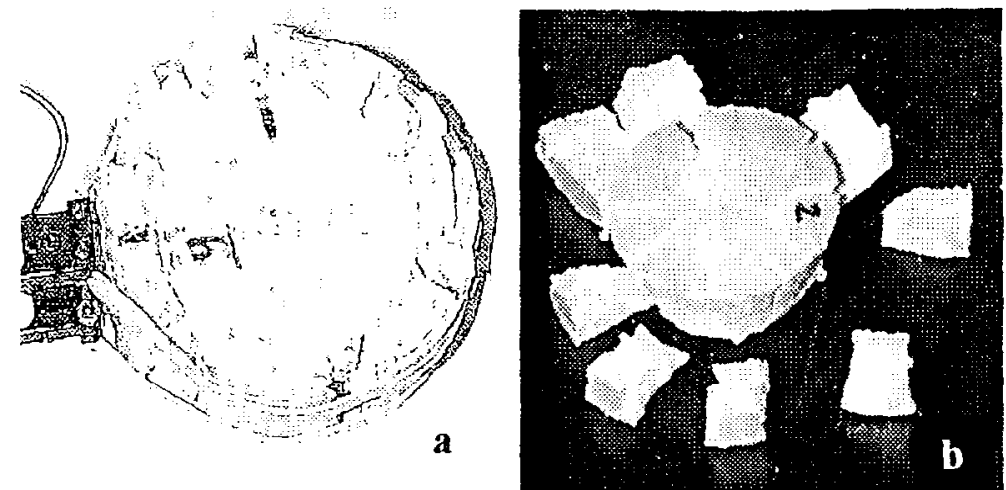

Figure 5. (a) LX-14 (2.54 cm $\times 5 \mathrm{~cm}$ dia.) and (b) $\mathrm{LX}-19$ fractured under $13.2 \mathrm{MPa}$ maximum compressive fatigue stress after 1600 and 11800 cycles, respectively.

A comparison of S-N data for LX-14 made from eight year old molding powder (filled circles, lot C-181) and LX-14 made from new molding power (filled squares, Lot C-211) shows higher modulus and longer cycle times to failure from nine year old LX-14. This is consistent with the static results discussed above. Samples from new LX-14 were softer and slightly less dense than the older lot. In the three samples of new LX-14 tested, the lot always failed earlier at constant stress levels even though these samples were pressed and tested under identical conditions. This is consistent with static tests above, but clearly inconsistent with previous aging data for LX-14..$^{15-17}$

The area within the hysteresis curves of LX-14 decreased during fatigue testing. Figure 6 shows the hysteresis loops for 3 cycles as a function of a logarithmic cycle time scale until just before failure. The first 3 cycles exhibit large irreversible strain (dynamic creep) during the measurement. Within 30 cycles, the irreversible strain has become small compared to the strain associated with the fatigue load over the time constant of the fatigue cycle. Then the hysteresis loops from the three cycles fall on top of each other. When the trace settles down, both elastic and plastic deformation can be observed during each cycle. Toward the middle of the cycle life, the area inside the hysteresis loop begins to decrease markedly and elastic and plastic character are no longer easily distinguished. Near the end of the fatigue life, the convex shape of the recovery cycle changes to a concave shape. When the sample fails, no consistent pattern is observed for several cycles prior to actual failure implying that fracture and flow are taking place. Figure 7 shows the increase in modulus as a function of number of cycles for LX-14 at various cyclic stresses. The rate of increase in stiffness seems to be independent of the maximum stress. 


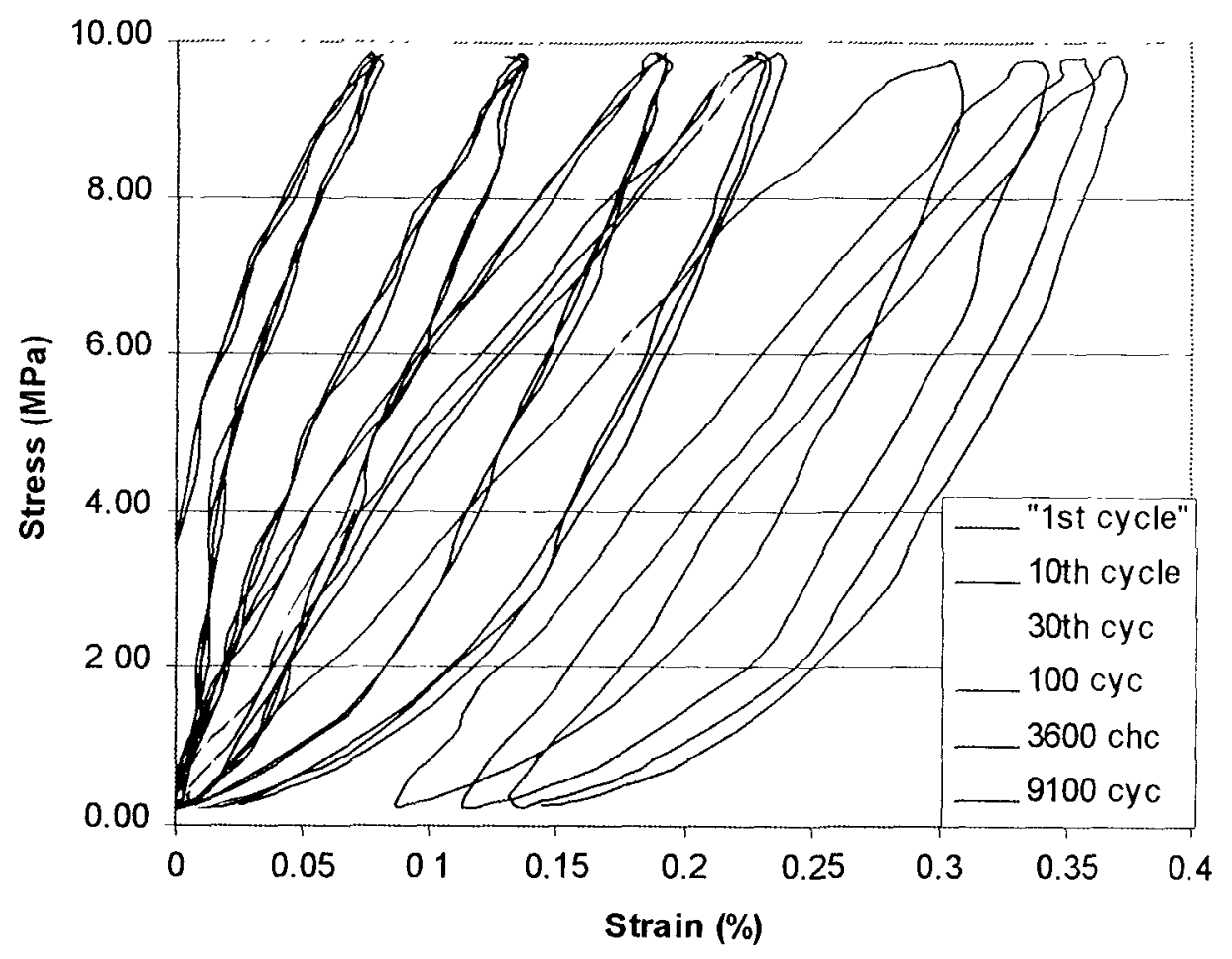

Figure 6. Fatigue cycles of LX-14 (C-181) at $10 \mathrm{MPa}$ after increasing cycle times show a definite increase in modulus and reduction in hysteretic loss.

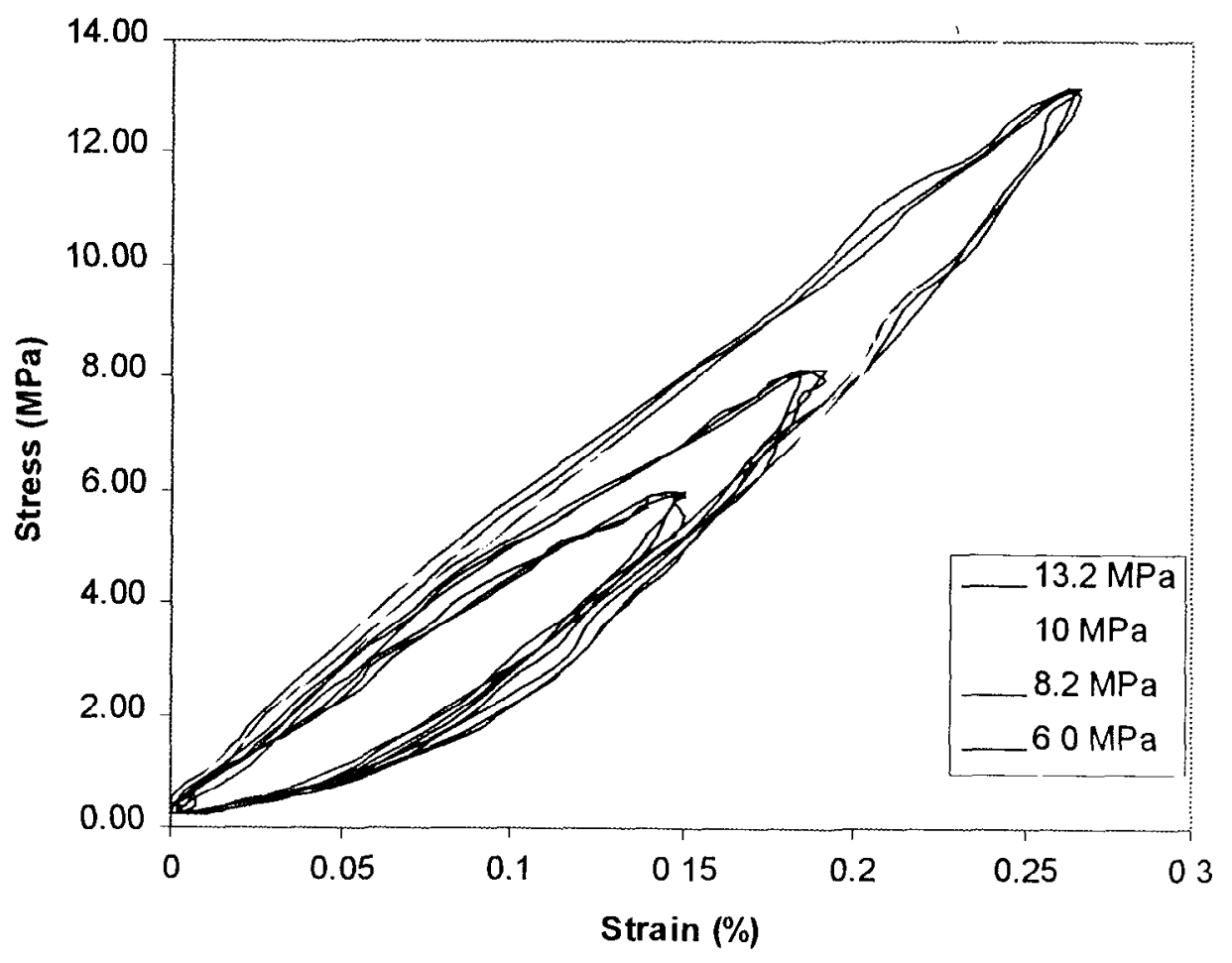

Figure 7. Similarity of hysteresis loops for LX-14 (lot C-181) at 30 cycles with increasing stress are similar, suggesting no change in fatigue mechanism. 
LX-14 and LX-19 tend to stress harden during compressive fatigue. The modulus may be calculated from the linear portion of the loading cycle or the average over the entire cycle (used in Fig. 8) with only a difference in the magnitude of the effect. The stroke or the extensometer strain may be used, again with only a difference in magnitude. Because of the tendency of the strain gauge to slip toward the end of the measurement the total displacement was used. Near the end of the fatigue life, the modulus drops dramatically as the sample cracks and flows under load. Note that both old and new LX-14 follow the same trend, but the new LX-14 intercepts the modulus axis at somewhat lower values. The modulus prior to failure versus number of cycles can be fitted to a weak power law of the form:

$$
\mathrm{E}(\text { cycle })=\mathrm{K} \cdot \mathrm{N}^{\mathrm{n}}
$$

Where $\mathrm{E}$ (cycle) is the modulus at a given cycle, $\mathrm{K}$ and $\mathrm{n}$ are constants and $\mathrm{N}$ is the number of cycles. For LX-14 from lot $C-181 K \approx 1.22$ and $n \approx 0.16$ while lot $C$ 211 gave $\mathrm{K} \approx 1.02$. The simplest explanation for the strain-hardening behavior is that the PBX is densifying under compression. This behavior is well known in pressing materials. ${ }^{3}$ However, recently a similar phenomenon has

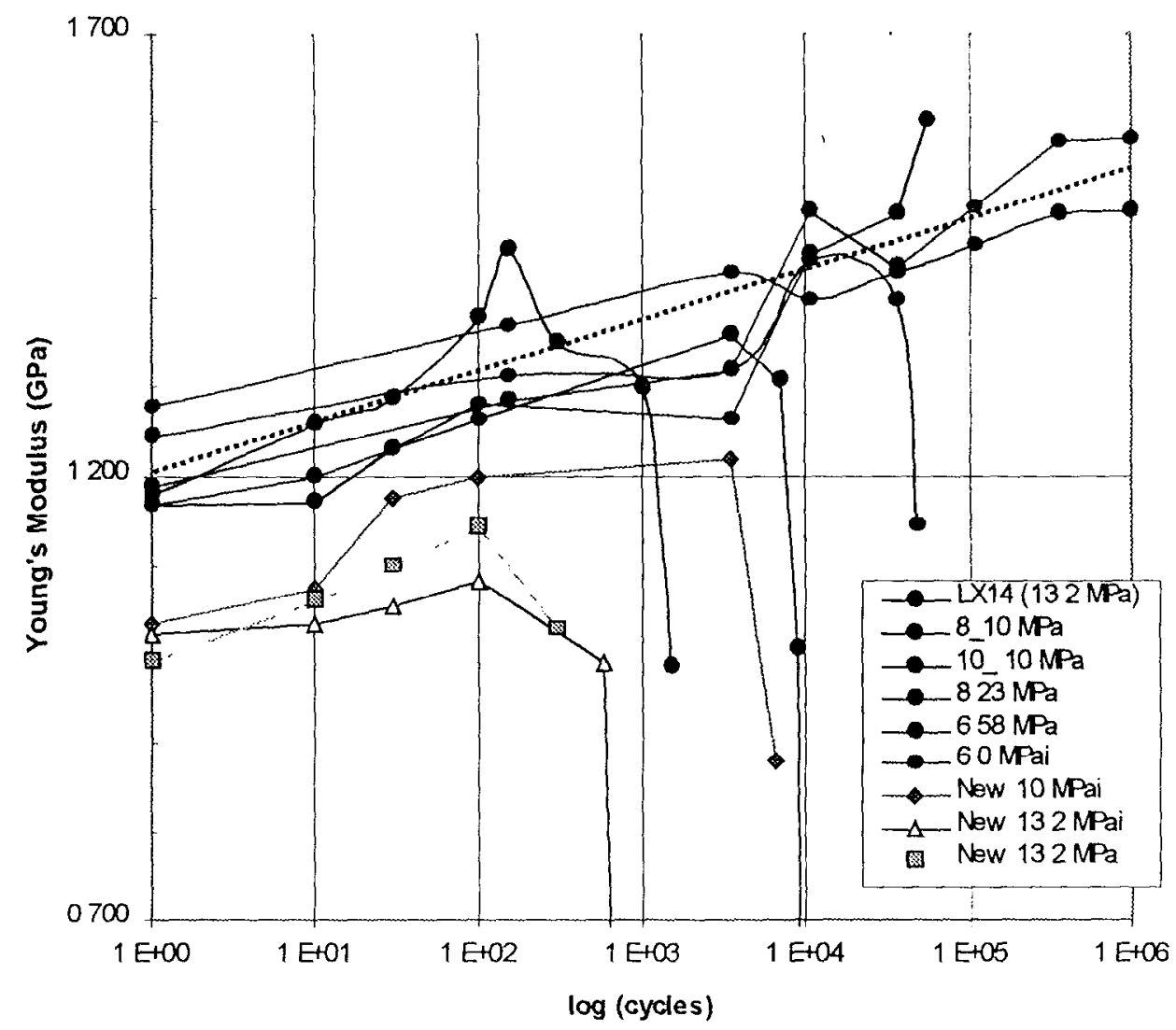

Figure 8. Stress hardening of LX-14 in compression is shown by the increase in modulus independent of the stress level. 
been observed in tensile fatigue. ${ }^{29,30}$ This may be associated with reorganization of the flaws or nucleation of cracks and crazes in the PBX. When cracks begin to propagate, the modulus drops off dramatically, so fatigue life and damage cannot be due to crack propagation alone.

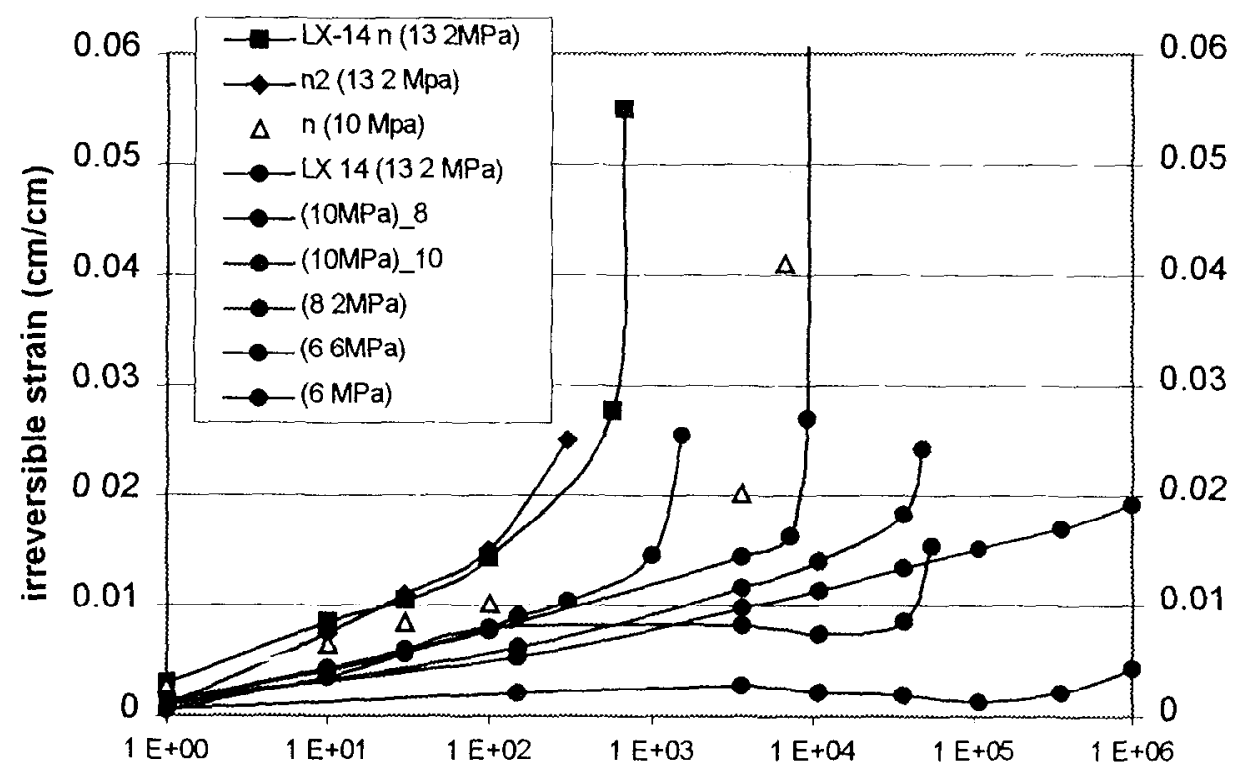

$\log$ (cycles)

Figure 9. Irreversible strain for LX-14 from lots C-211 and C-181 (diamonds) increased with increasing stress levels.

Irreversible strain (dynamic creep) is the permanent strain developed in the sample during fatigue. The irreversible strain for LX-14 from lots C-181 and $\mathrm{C}-211$ at various stress levels is given in Figure 8. As seen in the figure, the new LX-14 is somewhat softer than the old. With the exception of the $6 \mathrm{MPa}$ data from lot C-181, the dynamic creep seems to scale with the stress level. It would be interesting to compare conventional creep curves at these stress levels. One would expect that creep at the maximum stress would be greater than dynamic creep, but that the mean level dynamic creep would be greater than static creep.

Low magnification, reflected light pholomicrographs of the LX-14 surface prior to fatigue testing (Figure 9a) showed only the marks of the pressing operation and flaws in the die surface. In all figures pressure was applied from a ram in the pressing operations and from the fixture during testing in the vertical direction. When the explosive fails in fatigue, numerous medium-size cracks (several $\mathrm{mm}$ long by $30-50 \mu \mathrm{m}$ across) were observed on the surface of the specimen along with the catastrophic cracks (1-2 cm long) associated with failure 

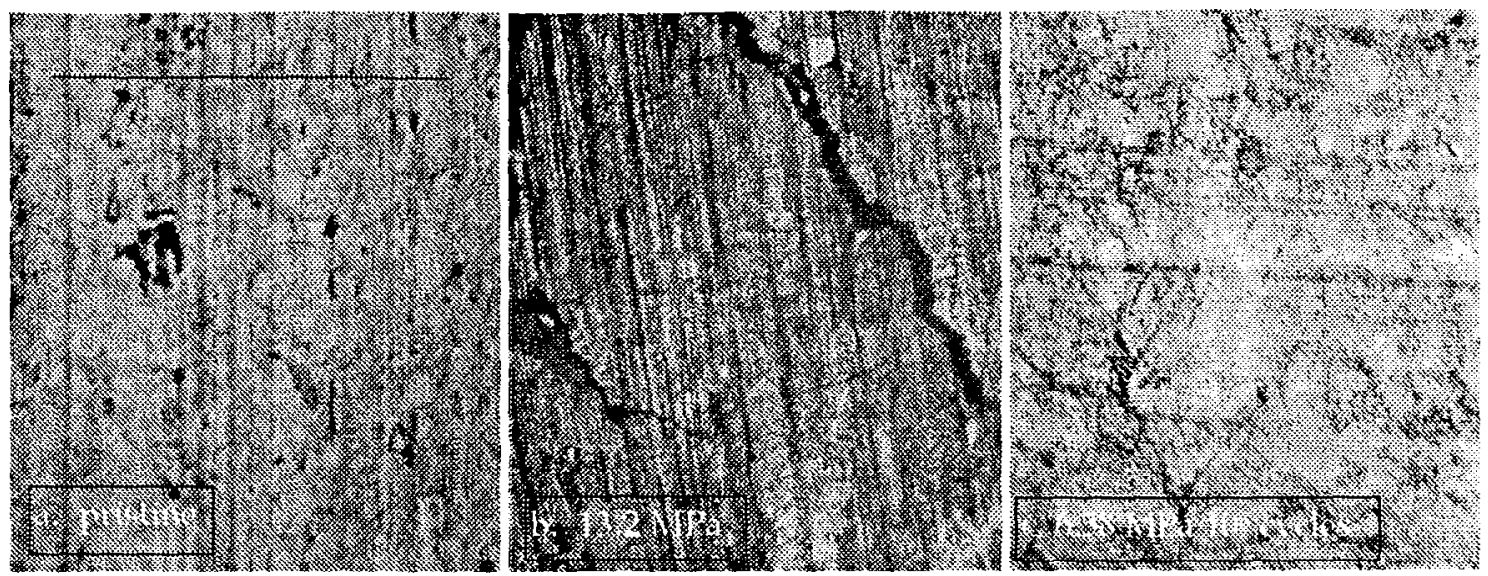

Figure 10. Optical micrographs of cylinder surfaces of (a) pristine LX-14 showed no damage, (b) fatigued failure LX-14 showed large cracks; and (c) after $10^{6}$ cycles without failure showed fine cracks.

shown in Figure $10 \mathrm{~b}$ and $\mathrm{c}$. Also much finer cracks ( $<1 \mathrm{~mm}$ long by $1-5 \mu \mathrm{m}$ across) were observed. In specimens which survived $10^{6}$ cycles, a few much finer cracks shown in Figures 10c were observed. One sample of LX-19 was removed after about 432,000 cycles at $8.23 \mathrm{MPa}(1200 \mathrm{psi})$ stress and then restarted and allowed to continue for another $10^{6}$ cycles. After 400,000 cycles the surface contained few observable cracks (Figure 7c); however the surface after 400,000 and $1.4 \times 10^{6}$ cycles was cracked almost to the point of failure. No fatigue limit was found in these plastic bonded explosives.

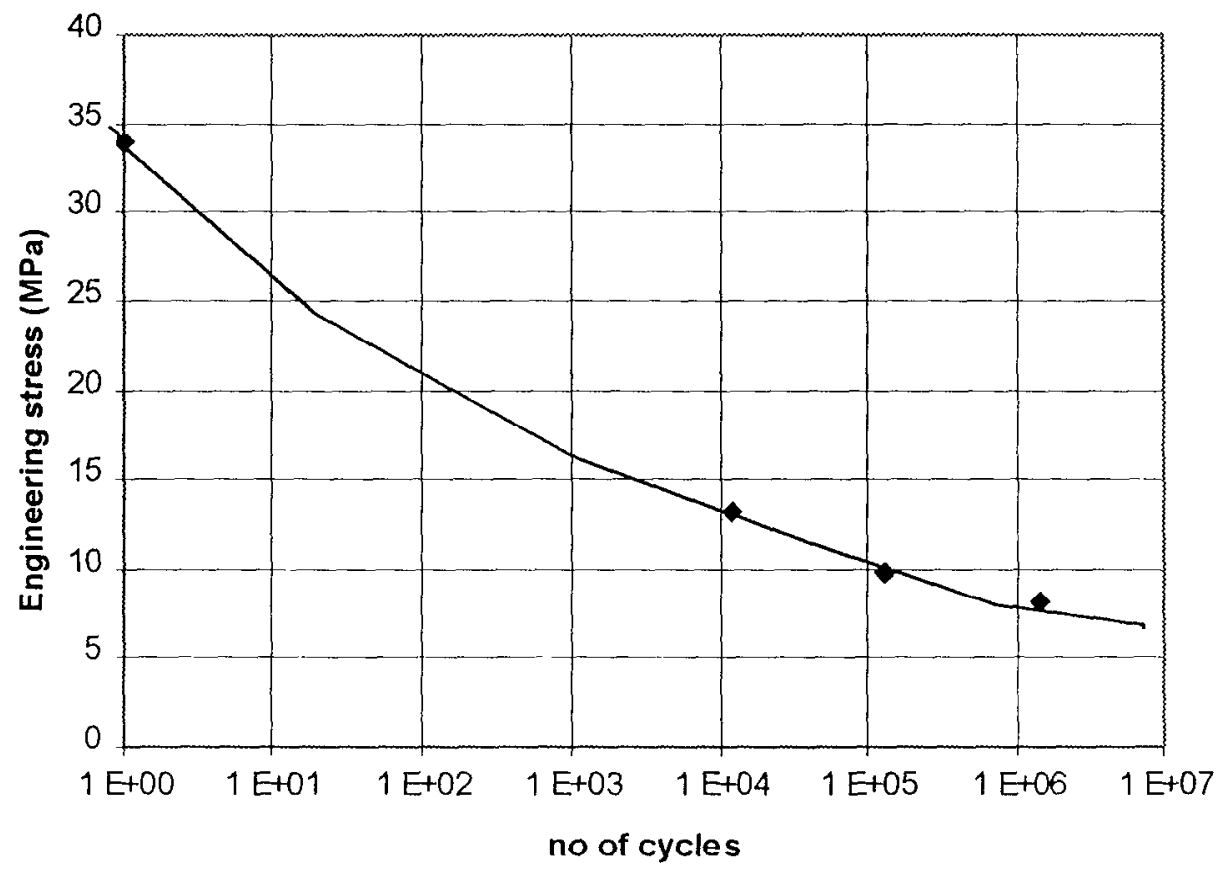

Figure 11. S-N curve for $\mathrm{LX}-19$ in compression at ambient at $1 \mathrm{~Hz}$. 
The S-N curve for LX-19 from lot C-205 at ambient is shown in Figure 11. The LX-19 S-N curve is shifted horizontally up the stress axis by about $20 \%$ compared to LX-14. LX-19 test cylinders failed in the same manner as LX-14 (see Figure 5). The LX-19 samples tested at stresses below $8.2 \mathrm{MPa}(1200 \mathrm{psi})$ survived $10^{6}$ cycles without failing, as compared to $6.6 \mathrm{MPa}$ (1000 psi) for LX-14. Changes in the modulus, hysteresis loop, and irreversible deformation occurred throughout these experiments in a similar manner to LX-14. This seems to imply that the mechanism of high cycle fatigue is similar in both PBXs. The improved fatigue strength in LX-19 may be associated with enhanced interfacial interactions between Estane 5703p and CL-20.

LX-19 also stress hardens during compressive fatigue. Figure 12 shows the increase in modulus as a function of number of cycles for LX-19 at three stress levels. The rate of increase in stiffness was independent of the maximum stress. The modulus curves nearly overlay the results for LX-14 (C-181), except that failure is extended to higher cycles, i.e., both old LX-14 and LX-19 follow the same trend, and can be fitted to equation 5 with similar parameters. For LX-19 from lot $C-206, K \approx 177000$ and $n \approx 0.16$ fit reasonably well. This result is consistent with the theory that the $\mathrm{PBX}$ is densifying under compression, except that one would expect a correlation between new LX-14 and LX-19, not old LX14 and new LX 19.

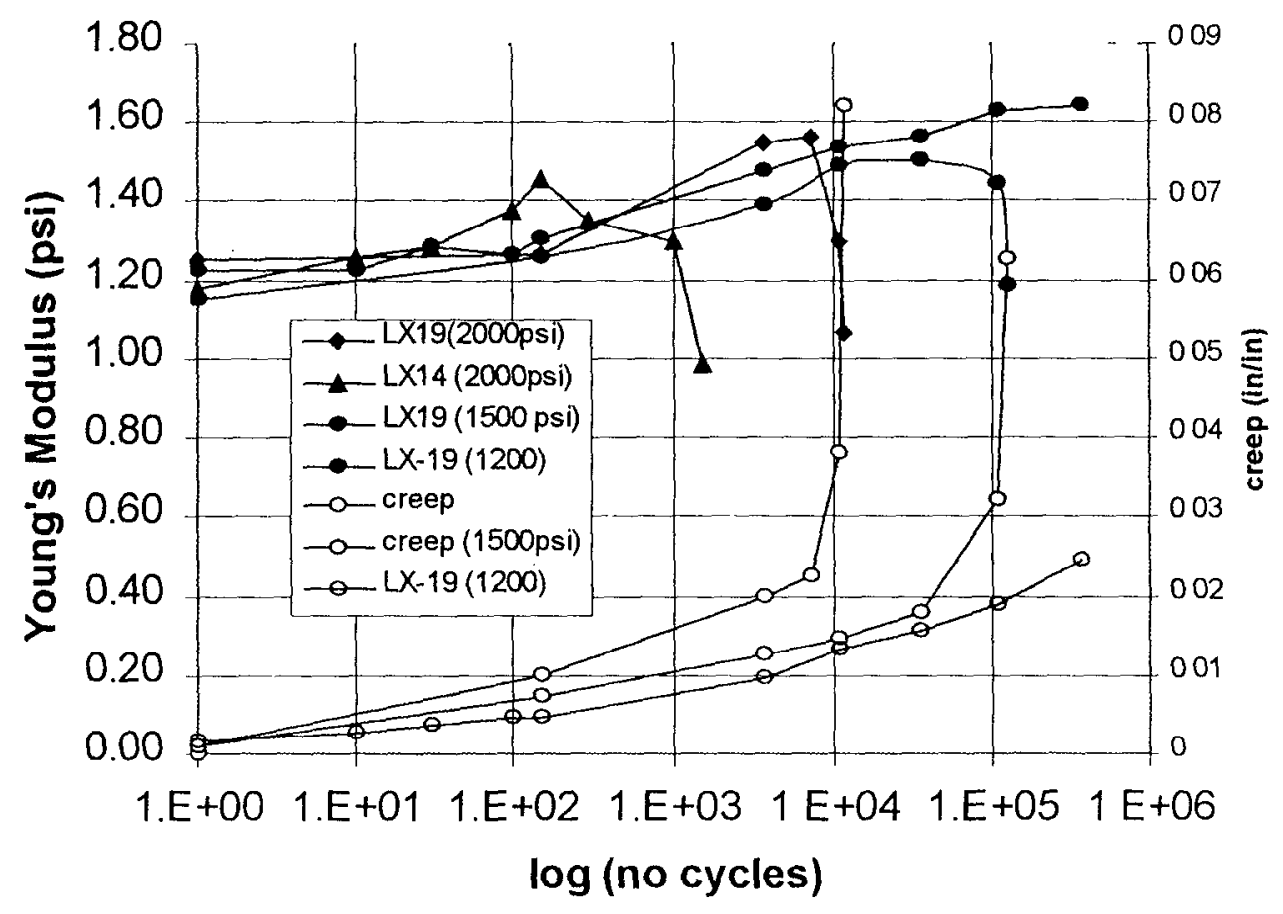

Figure 12. Stress hardening and associated irreversible strain in LX-19 during cyclic fatigue. 
The irreversible strain for LX-19 from lots C-206 at various stress levels is given in Figure 12 on the right $y$-axis. The dynamic creep scales nicely with the stress level. Comparison to data from LX-14 from C-211 and LX-19 at the same stress levels shows catastrophic motion occurs earlier in old LX-14. This result is consistent with the interaction of the Estane and HMX or CL-20 not having large effect on the modulus, but substantially influencing the failure characteristics.

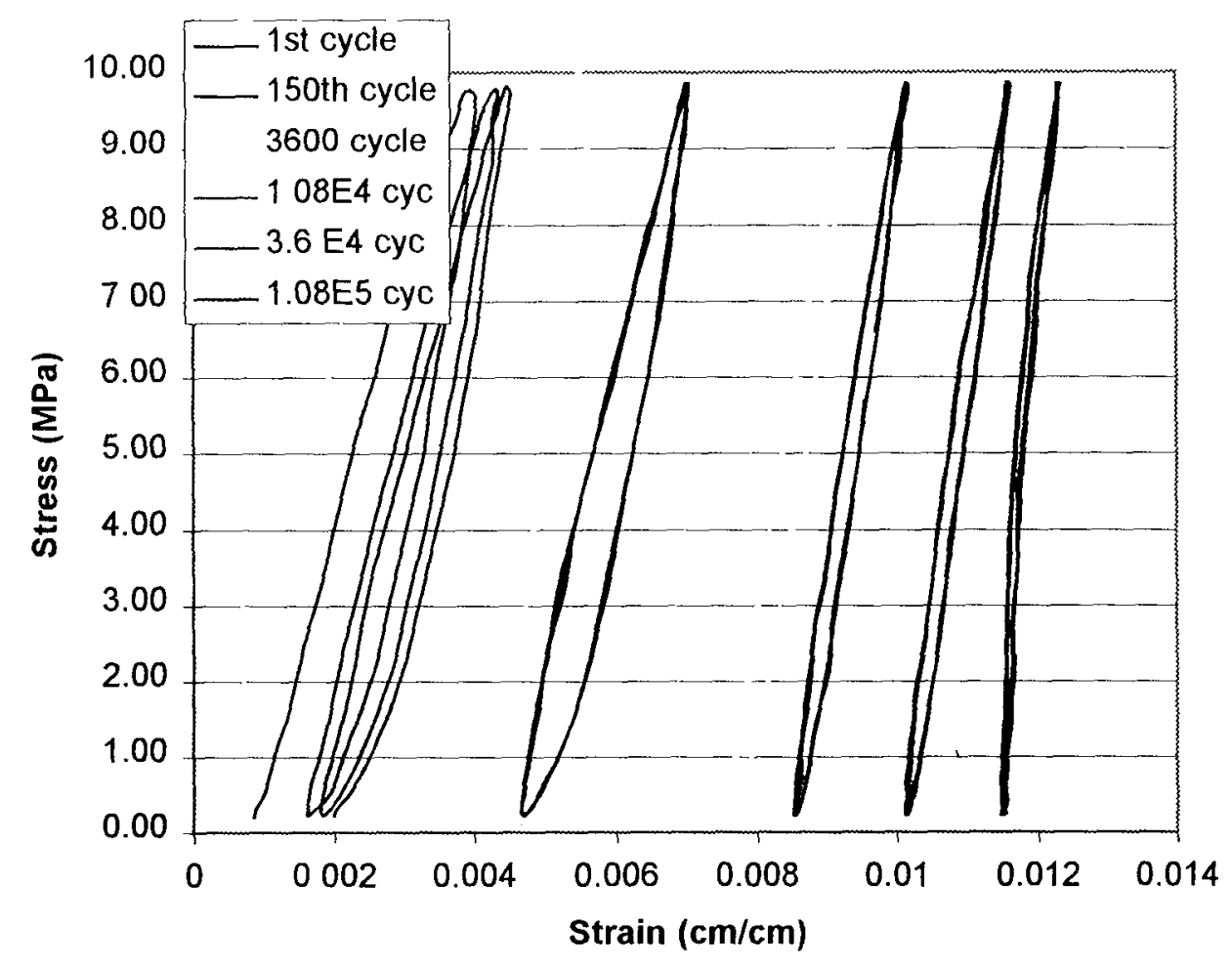

Figure 13. Fatigue cycles of LX-19 (C-206) at $10 \mathrm{MPa}$ plotted against total strain show an increase in modulus, reduction in hysteretic loss and irreversible strain.

Hysteretic losses are also similar to those found in LX-14 as shown in Figure 13. The area within the hysteresis curves of LX-19 decreased during fatigue testing. The hysteresis loops for 3 cycles plotted against total strain showed the effect of dynamic creep and reduced hysteresis very nicely. The first several hundred cycles exhibit large hysteretic losses. Toward the middle of the cycle life, the area of the hysteresis loop begins to decrease markedly, and elastic and plastic character are no longer casily distinguished. Near the end of the fatigue life, the convex shape of the recovery cycle changes to a concave shape. 


\section{Conclusions}

To our knowledge these data are the first S-N curves ever generated for a plastic bonded explosive in the mechanical fatigue regime. Measurements of propellant (with up to $80 \%$ solids) low cycle fatigue are well documented $27,33-36$, but no data was found for 95\% explosive filled PBXs. It is unlikely that compressive stresses in LLNL weapons will approach $6 \mathrm{MPa}$ (1000 psi) where the fatigue life of LX-14 and LX-19 exceeds $10^{6}$ cycles. Assuming a diurnal cycle caused by thermal stress $10^{6}$ cycles is equivalent to 2740 years. However, increases in the strain for a given stress have been observed in stockpile explosives. ${ }^{37}$ What effect the changes in fatigue properties have on an explosive's sensitivity is not known. XDF phenomena ${ }^{38}$ in extremely damaged explosives are well known. It should be possible to fatigue explosives, like LX14 or LX-19, at $6 \mathrm{MPa}$ for a hundred to a million cycles and evaluate changes in shock initiation and other sensitivity characteristics to insure that low level, long term fatigue does not sensitize these formulations.

\section{Acknowledgements}

Hank Andreski wrote the software fatigue program. Discussions with Steve De Teresa and Scott Groves are gratefully appreciated. Bruce Cunningham designed the protective cage. The Enhanced Surveillance program under the direction of Jeff Kaas funded a portion of the data acquisition hardware and test development. The encouragement and funding from the OM staff including $\mathrm{Al}$ Holt, Pam Kappelhof, and especially Stephanie Shang for her persistence in getting me to write it up.

\section{References.}

1. M. A. Mezger, (1993), Insensitive Munitions and Vulnerability Issues from the Army's POV, Presented at Lawrence Livermore National Laboratory.

2 E. L. Lee and C. M Tarver, Phys. Fluids 23, 2363 (1980).

3 Site 300 Explosives Safety Manual, Section 2- Process Area, no. 221 (Oct 20, 1993) Lawrence Livermore National Laboratory, Livermore CA.

4. MTS Teststar II Manual, MTS Corporation, Eden Prairie, MN.

5 ASTM E 606-92, Standard Practice for Strain-Controlled Fatigue Testing., American Society for the Testing of Materials, Philadelphia, PA.

6 R.L. Carlson and G.A Kardomateas, "An Introduction to Fatigue in Metals and Composites", Chapman \& Hall, London (1996)

7 R. W. Hertzberg and J. A. Mason, Fatigue of Engineering Plastics, Academic Press, New York (1980).

8. D. M. Hoffman, "Fatigue in Plastic Bonded Explosives: LX-14" in Joint DoD/DOE Munitions Technology Development Program FY96 Progress 
Report, (A.C. Holt and S. Lake, eds.) Lawrence Livermore National Laboratory, University of California, UCRL-ID-103482-96 (Jan 1997).

9. J.R. Humphrey, "LX-14, A New High-Energy Plastic-Bonded Explosive", Lawrence Livermore National Laboratory, University of California, UCRL 52350 , November 21, 1977

10. D.W. Brown, R. E. Cowry and L. E. Smith, Macromol., 13, 248 (1980).

11. R. L. Rabie, 'Kinetic Models of the Molecular Weight Change in Aging Estane", Los Alamos National Laboratory, University of Los Alamos, NM, LX-CP-95-119, (1995).

12. E. W. Grotheer, "Characterization of PBX Binders", Allied Signal, Kansas City Division, Kansas City, MO., BCX-613-3849 (1988).

13. E. Kohn and C. L. Martinez, "Size Excluxion Chromatography (XVIII). Molecular Characterization of Estane 5703 Baseline Values", Mason and Hanger-Silas Mason Co., Inc., Pantex Plant, Amarillo, TX, DOE/AL/650309503 (January 1995).

14. L.E. Caley and D. M. Hoffman, Org. Coatings and Plastics Chem. $\underline{44}$, 680-696, (1981).

15. E. M. Wewerka, E. D. Loughran and J. M. Williams, "The Effects of LongTerm Storage at Elevated Temperatrues on Small Cylinders of PBX 9501", Report No. UC-45, Los Alamos National Laboratory, University of California, (1976).

16. K. J. Scribner, "The Effect of Thermal Aging on ;the Sensitivity of LX-14", Lawrence Livermore National Laboratory, University of California, UCID 19039 (1981).

17. P. Foster, "Long-Term Compatibility Study of LX-14", MHSMP-78-28, Mason and Hanger, Inc., Pantex Plant, (1978).

18. M. L Matuszak and E. D. Loughran, Thermal Stability of PBX 9501" Los Alamos National Laboratory, University of Los Alamos, NM, LX-8156-MS, (February 1980).

19. A. E. Oberth, "Bonding Agent Review”, JANNAF Propulsion Meeting, Vol 3, part I pp. 337-368 CPIA Publ. No 250 Jan. 1976.

20. K. Kishor and P. Rajalingam, J. Appl. Polym. Sci., 372845 (1989).

21. C.S. Kim, P.N. Noble, C.H. Yount D. Tarrant and A. Gao, "The Mechanism of Filler Reinforcement from Addition of Neutral Polymer Bonding Agents oto Energetic Polar Propellant", Propellants, Explosives, Pyrotechnics, 17, 51 (1992)

22. G. M. Estes, S. L. Cooper, and A. V. Tobolsky, J. Macromol. Sci., Rev. Macromol. C4, 167 (1970).

23. Z. S. Petrovic and J. Furguson, "Polyurethane Elastomers" Prog. Polym. Sci., 16,695 (1991).

24. K. L. Hoy, J. Paint Techn. 4276 (1970).

25. D. W. van Krevelen, "Cohesive Properties and Solubility", Ch 7. In Properties of Polymers, Elsevier, New York, NY (1990) pp. 189-226.

26 R. J. Farris, Private communication (1996). 
27 J.F. Tormey and S, C, Britton, "Effect of Cyclic Loading on Solid Propellant Grain Structures Am. Inst. Aeronautics and Astronautics, 1, 1763-1770 (1963).

28 C. B. Bucknall, "Current Research on the Structure and Mechancial Properties of Rubber-Modified Thermoplastics", J. Mats. $\underline{4}$, 214 (1969)

29 A. J. Lesser," Changes in Mechanical Behavior During Fatigue of Semicrystalline Thermoplastics", J. Appl Polym. Sci. 58859 (1995).

30 A. J. Lesser, "Effective Volume Changes During Fatigue and Fracture of Polyacetal" Poly. Eng. Sci., 36, 2366 (1996).

31 F.N. Kelley, in Propellants Manufacturing, Hazards and Testing, Advances in Chemistry Series, 88, pp 188-243 (1969).

32 U. Yelmazer and R. J. Farris, "Mechanical Behavior and Dilatation of Particulate-Filled Thermosets in the Rubbery State", J. Appl Polym. Sci 28, 3369 (1983).

33 C. T. Liu and J. N. Yang, "Probabilistic Crack Growth Model for Application to Composite Solid Propellants", J. Spacecraft Rockets, 31, 79 (1994).

34 C. T. Liu, "Effect of Predamage on Crack Growth Behavior in a Particulate Composite Material", J. Spacecraft Rockets, 32, 533 (1995).

35 C. D. Bencher, R. H. Dauskardt, and R. O. Ritchie, "Microstructural Damage and Fracture Processes in a Composite Solid Rocket Propellant", J. Spacecraft Rockets, 32, 328 (1995).

36 R. A. Schapery, "Simplifications in the Behavior of Viscoelastic Composites with Growing Damage", MM 27010-90-8 Texas A\&M University, College Station, TX (1990).

37 A. W. Lundberg, private communication (1996).

38 H. W. Sandusky and R. R. Bernecker, "Influence of Fresh Damage on the Shock Reactivity and Sensitivity of Several Energetic Materials", Tenth International Detonation Symposium, ONR 33395-12, Office of Naval Research, Arlington VA (1993).

This work was performed under the auspices of the U.S. Department of Energy by Lawrence Livermore National Laboratory under contract No. W-7405-Eng-48. 


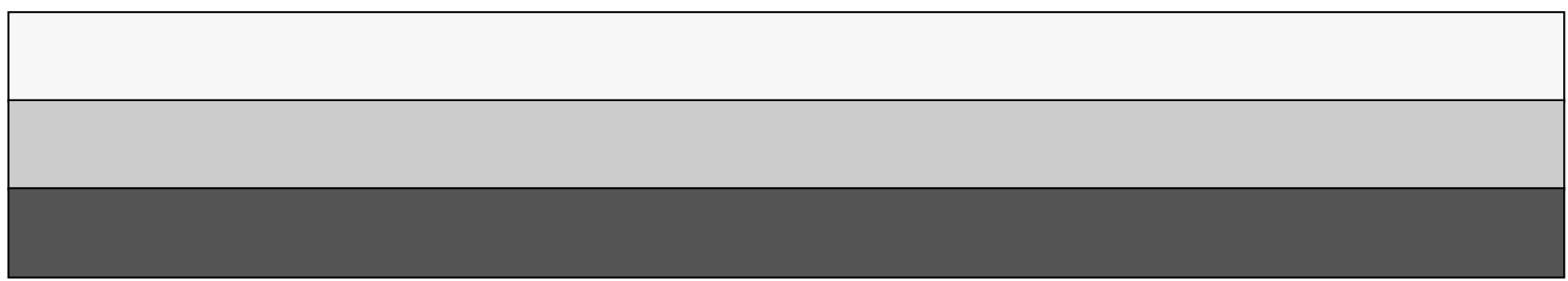

